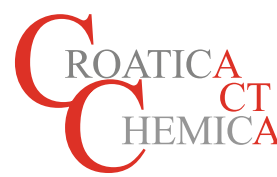

\title{
Reduction Potential of Ferrocenoyl-Substituted Nucleobases. Experimental and Computational Study
}

\author{
Valentina Havaić, ${ }^{1}$ Senka Djaković, ${ }^{2}$ Jasmina Lapić, ${ }^{2}$ Tin Weitner, ${ }^{1}$ Davor Šakić,,${ }^{1, *}$ Valerije Vrček ${ }^{1, \#}$
}

\footnotetext{
1 Faculty of Pharmacy and Biochemistry, University of Zagreb, Ante Kovačića 1, HR-10000, Zagreb, Croatia

2 Faculty of Food Technology and Biotechnology, University of Zagreb, Pierottijeva 6, HR-10000, Zagreb, Croatia

* Corresponding author's e-mail address: dsakic@pharma.hr

\# Corresponding author's e-mail address: vvrcek@pharma.hr
}

RECEIVED: October 11, 2017 * REVISED: February 12, 2018 * ACCEPTED: March 26, 2018

THIS PAPER IS DEDICATED TO PROF. MLADEN ŽINIĆ ON THE OCCASION OF HIS 70 TH BIRTHDAY

Abstract: Organometallic derivatives of nucleobases are characterized by distinctive biological and electrochemical properties. In this work, reduction potentials of ferrocenoyl-substituted nucleobases (uracil, 5-fluorouracil, and thymine) were measured by cyclic voltammetry and calculated by using density functional methods. Both experimental (281- $296 \mathrm{mV}$ ) and calculated (271-293 mV) values for reduction potential $E^{\prime \prime}$ show that these conjugates are much better oxidants than the parent ferrocene system. In search for the computational model, which can successfully reproduce experimental results, the M06-2X functional appeared as the optimal method in terms of efficiency and accuracy.

Keywords: redox potential, ferrocene, nucleobase, cyclic voltammetry, density functional.

\section{INTRODUCTION}

0 ORGANOMETALLIC nucleobase derivatives correspond to a new generation of conjugates in which metallocenes are linked to the basic structural elements of heredity. ${ }^{[1]}$ Due to their redox and bioactive properties, these conjugates are of use in bioanalytical ${ }^{[2]}$ and medicinal chemistry. ${ }^{[3,4]}$ Ferrocene, a prototypical metallocene, featuring characteristic sandwich-like structure with $\mathrm{Fe}^{2+}$ between two cyclopentadienyl rings $(C p)$ has been extensively explored in numerous copulates. ${ }^{[5]}$

Ferrocene part of the molecule undergoes a reversible one-electron oxidation and produces a stable ferrocenium cation. This important property has spurred ferrocene coupled molecules towards applications in the group of novel redox switches and electrochemical sensors. ${ }^{[6]}$ Pharmaceutical potential of ferrocene based sensors and/or marker has not yet been utilized, but a drug containing ferrocene, Ferroquine, has been registered for the use as an antimalarial agent. ${ }^{[7]}$ Intensive work has been done in search for a ferrocene containing drug with anticancer properties, ${ }^{[8]}$ where drugs' electrochemical potential may be used to turn off targeted enzymes in similar fashion as hydroxyurea works in interrupting ribonucleotide reductase enzyme. ${ }^{[9]}$

In search for bioorganometallic systems with an extended conjugation, the ferrocenoyl-substituted pyrimidine nucleobases (Scheme 1) have been prepared in our laboratory. ${ }^{[10]}$ In these chemical hybrids the two moieties (ferrocene and nucleobase) are linked by the carbonyl group. In this work we examine their redox properties by means of experimental and computational electrochemistry.

\section{EXPERIMENTAL AND COMPUTATIONAL DETAILS}

Electrochemical measurements on samples dissolved in acetonitrile with $0.1 \mathrm{M}$ tetraethylammonium tetrafluoroborate, $\left(\mathrm{NEt}_{4}\right)\left(\mathrm{BF}_{4}\right)$, as the supporting electrolyte were

(c) B. BY This work is licensed under a Creative Commons Attribution 4.0 International License. 
<smiles>[R]Oc1cccc(C(=O)n2cc([R])c(=O)[nH]c2=O)c1</smiles>

Scheme 1. Ferrocenoyl-substituted pyrimidine nucleobases $(1, R=H ; 2, R=F ; 3, R=M e)$.

performed at $25{ }^{\circ} \mathrm{C}$ using a $\mathrm{CH}$ Instruments $660 \mathrm{D}$ potentiostat with iR-drop compensation, on-line connected to a PC. All measurements were performed under argon atmosphere in an ALS VC-4 three-electrode glass cell containing a glassy carbon working electrode, a platinum wire auxiliary electrode (diameter $0.6 \mathrm{~mm}$ ) and an ALS RE7 nonaqueous silver reference electrode (RE). The RE consisted of a silver wire inserted into an acetonitrile solution of $0.01 \mathrm{M} \mathrm{AgNO}_{3}$ with $0.1 \mathrm{M}\left(\mathrm{NEt}_{4}\right)\left(\mathrm{BF}_{4}\right)$ and separated from the working solution by a Vycor tip. The GC electrode was polished with an aqueous alumina slurry with particles $0.05 \mu \mathrm{m}$ in diameter before every experiment and the electrode surface was determined to be $A=0.081$ $\pm 0.001 \mathrm{~cm}^{2}$ by chronocoulometry of a $2 \mathrm{mM}$ solution of $\mathrm{K}_{3}\left[\mathrm{Fe}(\mathrm{CN})_{6}\right]$ in $1 \mathrm{M}$ aqueous $\mathrm{KCl}$. ${ }^{[11]}$

The cyclic voltammetry (CV) measurements were recorded at scan rates varying between 20 and $200 \mathrm{mV} \cdot \mathrm{s}^{-1}$. All (relative) redox potentials are referenced against the ferrocene $\mathrm{Fc}^{+} / \mathrm{Fc}$ redox couple $\left(E^{\circ \prime}=0.00 \mathrm{~V}\right)$, as recommended by IUPAC. ${ }^{[12]}$ Parameters of the recorded cyclic voltammograms were evaluated according to previously published procedures. ${ }^{[13]}$ The cathodic and anodic current peak potentials, $E_{\mathrm{pc}}$ and $E_{\mathrm{pa}}$, were taken directly from the $\mathrm{CHI}$ software $\mathrm{v} 16.08$ and were used to calculate the half-wave potential, $E_{1 / 2}=\left(E_{\mathrm{pc}}+E_{\mathrm{pa}}\right) / 2$. The values of the apparent diffusion coefficients, $D_{\text {app }}$, were calculated from the dependence of the anodic peak current, $i_{\mathrm{pa}}$, on the scan rate, according to the RandlesSevcik equation. ${ }^{[14]}$ The apparent rates of electron transfer, $k^{\circ}{ }_{\text {app, }}$ were estimated from the polynomial model of dependence of current peak potential difference, $\Delta E_{\mathrm{p}}$, on $\log \psi,{ }^{[15]}$ assuming no significant difference between the diffusion coefficients of the oxidized and the reduced species (i.e. $D_{\mathrm{O}} \approx D_{\mathrm{R}}$ and $E_{1 / 2} \approx E^{\circ \prime}$ ). ${ }^{[16]}$ The values of $\Delta E_{\mathrm{p}} v s$. $\log \psi$ couples were obtained from data published by Nicholson. ${ }^{[17]}$ The obtained $k_{\text {app }}^{\circ}$ values are the rates of electron exchange in the condition of $E=E^{\circ}$, i.e. when the rates of both reduction and oxidation reactions have the same value equal to $k^{\circ}$ app, which represents a measure of the kinetic facility of a redox couple. [Error! Bookmark not defined.] The apparent radii of solvent cavities, $r_{\mathrm{app}}$, were calculated according to the known Stokes-Einstein relation, $r_{\mathrm{app}}=$ $k_{\mathrm{B}} T /\left(6 \pi \eta D_{\mathrm{app}}\right)$, where $k_{\mathrm{B}}$ is the Boltzmann constant and $\eta=$ $0.344 \times 10^{-3} \mathrm{~kg} \mathrm{~m}^{-1} \mathrm{~s}^{-1}$ is the viscosity of acetonitrile. ${ }^{[18]}$

All geometries were optimized on the M06-2X and B3LYP levels of theory, as implemented in the Gaussian 09 software package. ${ }^{[19]}$ The basis set for optimization was standard Pople's 6-311G(d) on non-metal atom centers, while Stuttgart-Dresden (SDD) ${ }^{[20]}$ basis set with effective core potential (ECP) was used for Fe, similar to previous studies. ${ }^{[21]}$ Wave function stability test was performed on all species. Harmonic frequencies were computed from analytical second derivatives at the corresponding level of theory.

Gibbs energies of solvation were determined by single-point calculations using the PCM continuum solvation model at the B3LYP/6-311G(d)//B3LYP/6-311G(d) level, with the UFF atomic radii and electrostatic scaling factor (alpha value) set to 1.1 for all atoms (default values in Gaussian09).[22,23] The solvent relative permittivity of $\varepsilon=35.688$ (acetonitrile) was used.

\section{RESULTS AND DISCUSSION}

\section{Electrochemical Measurements}

Electrochemical parameters $E^{\circ \prime}, k_{\text {app }}^{\circ}, D_{\text {app }}$ and $r_{\text {app }}$ are summarized in Table 1 , and corresponding cyclic voltammograms are presented in Figure 2. Ferrocenylsubstituted nucleobases exhibit a reversible one-electron redox behaviour. All measured redox potentials $E^{\circ \prime}$ are 281-296 mV above the value of the reference ferrocene redox couple $\mathrm{Fc}^{+} / \mathrm{Fc}$. This indicates that oxidation of the ferrocenyl units in conjugates with nucleobases is considerably more difficult than that of ferrocene itself. The increased difficulty in oxidation can be interpreted in terms of the carbonyl group effect. The electron withdrawing effect of this group, attached directly to the cyclopentadiene ring, makes the oxidation of the iron centre more difficult (Figure 1).

In cases where the carbonyl group was replaced by the methylene group, as in ferrocenylmethylthymine and ferrocenlymethyluracil, the reduction potentials were shifted toward the value of the reference couple (87 and $135 \mathrm{mV}$, resp.).[24]

Different substitutions at the C5-position of the pyrimidine ring have negligible effect on the redox properties of the ferrocenoyl-nucleobase system, as all the measured potentials are lying in the range of only $15 \mathrm{mV}$. 


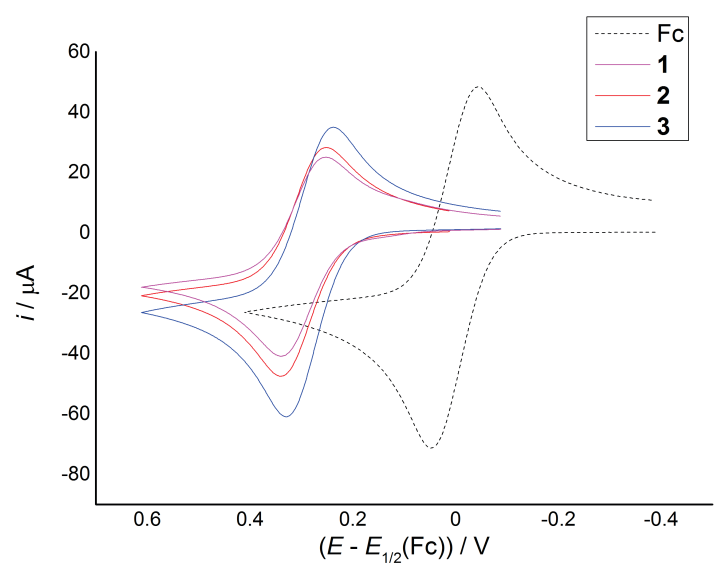

Figure 1. Cyclic voltammograms of ferrocenoyl-nucleobase conjugates, 1,2 , and 3 , and $\mathrm{Fc}$ in acetonitrile at $25^{\circ} \mathrm{C}$ (supporting electrolyte $0.1 \mathrm{M}\left(\mathrm{NEt}_{4}\right)\left(\mathrm{BF}_{4}\right)$ ), at a scan rate of $100 \mathrm{mV} \mathrm{s}^{-1}$. All potentials are referenced to $\mathrm{Fc}^{+} / \mathrm{Fc}$.

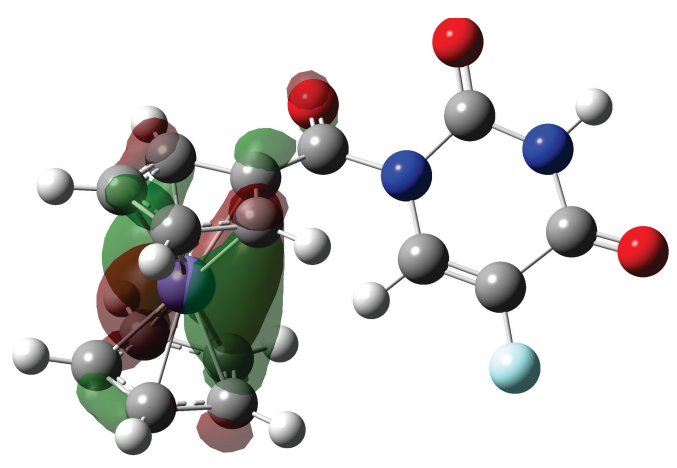

Figure 2. The HOMO (MO82 calculated at the B3LYP/6$311 G(d) / S D D$ level) in the ferrocenoyl-5-fluorouracil (reduced form) belongs to the iron-centered $d_{x^{2}-y^{2}}$ orbital with some delocalization to the carbonyl group.

Table 1. Electrochemical data for 1, 2, 3, and Fc.

\begin{tabular}{ccccc}
\hline & $\begin{array}{c}E^{\prime \prime} / \mathrm{mV} \\
\text { vs. } \mathrm{Fc}^{+} / \mathrm{Fc}\end{array}$ & $\begin{array}{c}k_{\mathrm{app}}^{\circ} / \\
10^{-2} \mathrm{~cm} \mathrm{~s}^{-1}\end{array}$ & $\begin{array}{c}D_{\mathrm{app}} / \\
10^{-5} \mathrm{~cm}^{2} \mathrm{~s}^{-1}\end{array}$ & $\mathrm{r}_{\mathrm{app}} / \AA$ \\
\hline 1 & 296 & 1.23 & 1.73 & 3.7 \\
2 & 294 & 1.01 & 2.04 & 3.1 \\
3 & 281 & 1.27 & 1.73 & 3.7 \\
$\mathrm{Fc}$ & 0 & 1.31 & 2.28 & 2.8 \\
\hline
\end{tabular}

\section{Computational Electrochemistry}

Due to high requirements for achieving results of predictive quality, reduction potentials are good target properties for the evaluation by electronic structure methods. A number of theoretical studies have addressed the question of how to get accurate result for redox potentials, focusing on various chemical systems and different computational models. ${ }^{[25,26]}$ As expected, different chemical systems require different computational models to correctly calculate their redox properties. ${ }^{[27]}$

There may be a problem with selection of theoretical model appropriate to calculate redox potential for larger compounds which comprise of two (or more) molecular moieties. For example, in the nucleoside the pyrimidine (or purine) ring is connected to the sugar part of the molecule. For each of the two fragments, nucleobase and sugar, suitable computational methods are determined, but not for the nucleoside system as a whole. [28]

Here, we explore conjugates of type $\mathrm{Fc}-\mathrm{CO}-\mathrm{B}$ in which organometallic part ( $\mathrm{FC}=$ ferrocene) and nucleobase ( $B=$ uracil, thymine, or fluorouracil) are connected by the carbonyl linker (CO). According to literature reports, two different parts of ferrocene-nucleobase conjugates require different theoretical approaches to correctly calculate their redox properties. Thus, ferrocene itself and its redox property was properly described with the composite model G3(MP2)-RAD-Full-TZ, as reported by Coote and coworkers. ${ }^{[29]}$ On the other side, the CBS-QB3 and G3B3 models were benchmarked as superior to calculate redox properties of nucleobases. ${ }^{[28]}$ These benchmarking studies were performed on separated systems, i.e. nucleobase and ferrocene as isolated moieties in each case. However, for larger chemical systems, i.e. ferrocenyl derivatives of nucleobases (Fc-CO-B), these sophisticated composite models may become impractical.

In the search for theoretical model which is efficient and optimal both for ferrocene and nucleobase derivatives, the B3LYP method and M06 family of density functionals appeared as good candidates. These methods were used by different authors to determine redox potentials of nucleobases and ferrocene, and good agreement with experiments was obtained. Thus, the B3LYP functional was employed to calculate redox potentials of nucleobases ${ }^{[30]}$ and transition metal complexes, including ferrocene. ${ }^{[31]}$ The $6-31+G(d, p)$ and $6-311 G(d)$ basis sets were used, respectively. In the latter study, the metal center was described by the nonrelativistic effective core potential of the LANL2DZ basis set. In addition, the B3LYP functional was recently used to calculate redox potential of ferrocene, ${ }^{[32]}$ together with several functionals from the Truhlar group (M05, M06, and M06L). Again, the 6-311G(d) basis set was used for all atoms, except the iron which was described with the LANL08 or SDD basis set. Finally, the functionals from the Minnesota series (M06 and M06-2X) were also used in calculation of the one-electron redox properties of nucleobases, together with the $6-31++G(d, p)$ basis set. ${ }^{[33,34]}$ 


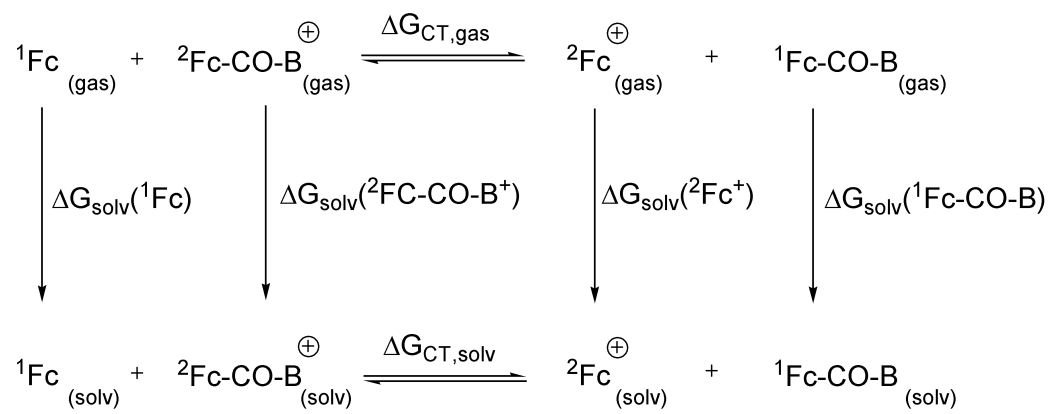

Figure 3. Thermodynamic cycle for a charge transfer (CT) reaction.

In all cases investigated, the DFT models were reported as reliable methods for calculations of the redox potential for each respective system (i.e. ferrocene or nucleobases). Therefore, we have selected them to calculate redox properties of pyrimidine-ferrocene conjugates. We decided to use the M06-2X/6-311G(d) and B3LYP/6-311G(d) which include density functional and basis set validated earlier as reliable tools (see above) for redox property calculations. In this work the methods were identified as optimal for describing redox properties of ferrocene-nucleobase conjugates $\mathbf{1}, \mathbf{2}$, and $\mathbf{3}$, and results obtained at these levels were used throughout the text. In each case the iron was described by SDD basis set, and solvent effects were modeled with SCRF/PCM model.

Isodesmic reaction protocol was used to calculate redox potential of ferrocene-nucleobase conjugates $\mathrm{Fc}-\mathrm{CO}$ $B$, where $B$ is uracil (1), 5 -fluorouracil (2), or thymine (3). In this protocol redox potentials of ferrocene-nucleobase conjugates [Eq. (1)] are referenced with respect to the redox potential of the ferrocenium / ferrocene $\left(\mathrm{Fc}^{+} / \mathrm{Fc}\right)$ couple [Eq. (2)].

$$
\begin{aligned}
& { }^{2}(\mathrm{Fc}-\mathrm{CO}-\mathrm{B})^{+}+\mathrm{e}^{-} \rightarrow{ }^{1} \mathrm{Fc}-\mathrm{CO}-\mathrm{B} \\
& { }^{2} \mathrm{Fc}^{+}+\mathrm{e}^{-} \rightarrow{ }^{1} \mathrm{Fc}
\end{aligned}
$$

where ${ }^{1} \mathrm{Fc}$ represents ferrocene singlet state (the central atom formal charge is $\mathrm{Fe}^{2+}$ ) in the eclipsed conformation (D5 $\mathrm{h}$ point group), and ${ }^{2} \mathrm{Fc}^{+}$is the ferrocenium doublet (the central atom formal charge is $\mathrm{Fe}^{3+}$ ) also in the eclipsed conformation. ${ }^{[35]}$ The ${ }^{2}(\mathrm{Fc}-\mathrm{CO}-\mathrm{B})^{+}$and ${ }^{1} \mathrm{Fc}-\mathrm{CO}-\mathrm{B}$ represent an oxidized and reduced form of ferrocene-nucleobase conjugates 1, 2, or 3, with no symmetry constraints (Figure 4).

Combining [Eq. (1)] and [Eq. (2)] gives an overall redox reaction which corresponds to an isodesmic charge transfer (CT) reaction [Eq. (3)].

$$
{ }^{1} \mathrm{Fc}+{ }^{2}(\mathrm{Fc}-\mathrm{CO}-\mathrm{B})^{+}+\mathrm{e}^{-} \rightarrow{ }^{2} \mathrm{Fc}^{+}+{ }^{1} \mathrm{Fc}-\mathrm{CO}-\mathrm{B}
$$

For the charge-transfer reaction between $\mathrm{Fc}-\mathrm{CO}-\mathrm{B}$ and a reference molecule $(\mathrm{Fc})$ the standard potential $E^{\circ}\left({ }^{2} \mathrm{Fc}-\mathrm{CO}-\mathrm{B}^{+} /{ }^{1} \mathrm{Fc}-\mathrm{CO}-\mathrm{B}\right)$ may be obtained from the thermodynamic cycle in Figure 3 and Equations 4 and 5 .

$$
\begin{aligned}
& \Delta G_{\text {CT, solv }}=\Delta G_{\text {CT,gas }}+\Delta G_{\text {solv }}\left({ }^{2} \mathrm{Fc}^{+}\right)+ \\
& \Delta G_{\text {solv }}\left({ }^{1} \mathrm{FC}-\mathrm{CO}-\mathrm{B}\right)-\Delta G_{\text {solv }}\left({ }^{1} \mathrm{FC}\right)-\Delta G_{\text {solv }}\left({ }^{2} \mathrm{Fc}-\mathrm{CO}-\mathrm{B}^{+}\right) \\
& E^{\mathrm{o}^{\prime}}\left({ }^{2} \mathrm{Fc}-\mathrm{CO}-\mathrm{B}^{+} /{ }^{1} \mathrm{Fc}-\mathrm{CO}-\mathrm{B}\right)=\Delta G_{\mathrm{CT}, \text { solv }} / n \mathrm{HF}
\end{aligned}
$$

where $E^{\prime \prime}\left({ }^{2} \mathrm{Fc}-\mathrm{CO}-\mathrm{B}^{+} /{ }^{1} \mathrm{Fc}-\mathrm{CO}-\mathrm{B}\right)$ is the standard reduction potential for ferrocene-nucleobase conjugate, $F$ is Faraday constant (96485 $\mathrm{C} \mathrm{mol}^{-1}$ ), and $n$ is number of electrons transferred.

This alternative approach may be more accurate by systematic error cancellation. ${ }^{[36]}$ An added advantage of the protocol is that the absolute potential of the standard hydrogen electrode is no longer needed, thereby eliminating a source of uncertainty.

Experimental redox potentials of ferrocenoyl-substituted nucleobases 1, 2, and $\mathbf{3}$ (Table 1) were reproduced computationally (Table 3 ). In case of results calculated at the B3LYP level, all values are somewhat overestimated by an average factor of 1.09. This suggests that an additional benchmarking and scaling of calculated values would be beneficial. A better agreement with experimental results is

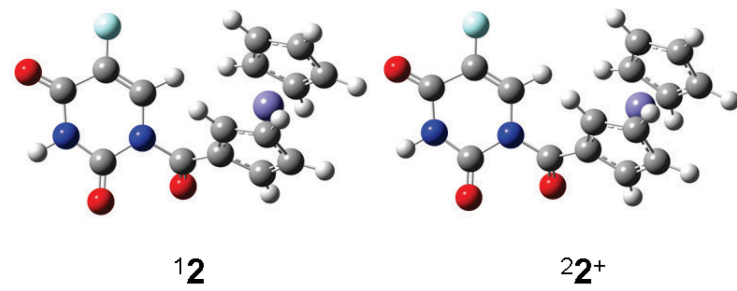

Figure 4. B3LYP/6-311G(d) optimized geometries of the reduced form of ferrocenoyl-substituted 5-fluorouracil ( 12 , singlet state in which the central atom formal charge is $\mathrm{Fe}^{2+}$ ) and its oxidized form $\left({ }^{2} 2^{+}\right.$, doublet state in which the central atom formal charge is $\mathrm{Fe}^{3+}$ ). 
Table 2. Gibbs free energies (in $\left.\mathrm{kJ} \mathrm{mol}^{-1}\right)$ for charge transfer reaction in gas $\left(\Delta G_{\mathrm{CT}, \text { gas }}\right)$ and acetonitrile $\left(\Delta G_{\mathrm{CT} \text {, solv }}\right)$, and solvation free energies $\left(\Delta G_{\text {solv }}\right)$ for all species involved in the thermodynamic cycle presented in Figure 3 and Equation 4.

\begin{tabular}{|c|c|c|c|c|c|c|c|}
\hline & \multirow{2}{*}{$\mathrm{Fc}-\mathrm{CO}-\mathrm{B}$} & \multicolumn{3}{|c|}{ B3LYP(a) } & \multicolumn{3}{|c|}{ M06-2X(b) } \\
\hline & & $\Delta G_{\mathrm{CT} \text {,gas }}$ & $\Delta G_{\text {solv }}$ & $\Delta G_{\mathrm{CT}, \text { solv }}$ & $\Delta G_{\mathrm{CT}, \mathrm{gas}}$ & $\Delta G_{\text {solv }}$ & $\Delta G_{\mathrm{CT}, \text { solv }}$ \\
\hline \multirow[b]{2}{*}{1} & ${ }^{1} \mathrm{Fc}-\mathrm{CO}-\mathrm{U}$ & \multirow[b]{2}{*}{-16.1} & -41.3 & \multirow[b]{2}{*}{30.4} & \multirow[b]{2}{*}{-25.6} & -43.6 & \multirow[b]{2}{*}{28.3} \\
\hline & ${ }^{2} \mathrm{Fc}-\mathrm{CO}-\mathrm{U}^{+}$ & & -198.9 & & & -201.3 & \\
\hline \multirow[b]{2}{*}{2} & ${ }^{1} \mathrm{Fc}-\mathrm{CO}-5 \mathrm{FU}$ & \multirow[b]{2}{*}{-47.9} & -50.5 & \multirow[b]{2}{*}{30.5} & \multirow[b]{2}{*}{-73.9} & -52.0 & \multirow[b]{2}{*}{27.8} \\
\hline & ${ }^{2} \mathrm{Fc}-\mathrm{CO}-5 \mathrm{FU}^{+}$ & & -239.7 & & & -225.0 & \\
\hline \multirow[b]{2}{*}{3} & ${ }^{1} \mathrm{Fc}-\mathrm{CO}-\mathrm{T}$ & \multirow[b]{2}{*}{-9.5} & -40.1 & \multirow[b]{2}{*}{31.1} & \multirow[b]{2}{*}{-13.8} & -42.4 & \multirow[b]{2}{*}{26.2} \\
\hline & ${ }^{2} \mathrm{Fc}-\mathrm{CO}-\mathrm{T}^{+}$ & & -191.9 & & & -192.7 & \\
\hline \multirow[b]{2}{*}{$\mathrm{Fc}$} & ${ }^{1} \mathrm{FC}$ & \multirow[b]{2}{*}{-} & -11.1 & \multirow[b]{2}{*}{-} & \multirow[b]{2}{*}{-} & -13.3 & \multirow[b]{2}{*}{-} \\
\hline & ${ }^{2} \mathrm{Fc}$ & & -182.9 & & & -173.6 & \\
\hline
\end{tabular}

(a) PCM-B3LYP/6-311G(d)/SDD.

(b) PCM-M06-2X/6-311G(d)/SDD.

Table 3. Calculated redox potentials ( $\left.E^{\circ \prime}\right)$ for 1,2 , 3, and Fc at different level of theory, according to the Equation 5. Experimental values included for comparison reasons.

\begin{tabular}{|c|c|c|c|}
\hline & \multicolumn{3}{|c|}{$E^{\circ \prime} / \mathrm{mV}\left(v s . \mathrm{Fc}^{+} / \mathrm{Fc}\right)$} \\
\hline & B3LYP(a) & M06-2X & Exp. \\
\hline 1 & 315 & 293 & 296 \\
\hline 2 & 316 & 288 & 294 \\
\hline 3 & 322 & 271 & 281 \\
\hline Fc & 0 & 0 & 0 \\
\hline
\end{tabular}

(a) PCM-B3LYP/6-311G(d)/SDD

(b) PCM-M06-2X/6-311G(d)/SDD.

obtained if M06-2X functional is used. In addition to a better numerical agreement, the M06-2X functional also gives an accurate trend in the obtained values, compared to experimental electrochemical potentials. Therefore, this method, already proposed by some authors as optimal in terms of efficiency and accuracy, is recommended for calculations of redox potentials of conjugates which contain organometallic and heterocyclic fragments.

\section{CONCLUSION}

Organometallic derivatives of pyrimidine nucleobases were prepared in our laboratory and their electroactive properties were investigated by use of cyclic voltammetry and quantum-chemical methods. It was shown that these conjugates are more resistant to reduction, i.e. they are better oxidant than the parent ferrocene. Experimental results obtained by cyclic voltammetry were reproduced by B3LYP and M06-2X models, the two functionals, which were proposed earlier as reliable DFT methods. We found that the Minnesota functional is a better choice for calculation of redox potentials of ferrocenoyl-substituted nucleobases.

Acknowledgment. This work was fully supported by the Croatian Science Foundation under the project IP-2016-061137.

\section{REFERENCES}

[1] K. Kowalski, Coord. Chem. Rev. 2016, 317, 132.

[2] J. Liu, H. Zhou, J.-J. Xu, H.-Y. Chen, Chem. Commun. 2011, 47, 4388.

[3] K. Kowalski, L. Szczupak, S. Saloman, D. Steverding, A. Jablonski, V. Vrček, A. Hildebrandt, H. Lang, A. Rybarczyk-Pirek, ChemPlusChem 2017, 82, 303.

[4] E. Lewandowski, L. Szczupak, S. Wong, J. Skiba, A. Guspiel, J. Solecka, V. Vrček, K. Kowalski, Y. Chen, Organometallics 2017, 36, 1673.

[5] K. Heinze, H. Lang, Organometallics 2013, 32, 5623.

[6] R. Sun, L. Wang, H. Yu, Zain-ul-Abdin, Y. Chen, J. Huang, R. Tong, Organometallics 2014, 33, 4560.

[7] D. R. Van Staveren, N. Metzler-Nolte, Chem. Rev. 2004, 104, 5931.

[8] C. Ornelas, New J. Chem. 2011, 35, 1973.

[9] A. Singh, Y.-J. Xu, Genes 2016, 7, 99.

[10] J. Lapić, V. Havaić, D. Šakić, K. Sanković, S. Djaković, V. Vrček, Eur. J. Org. Chem. 2015, 5424.

[11] S. J. Konopka, B. McDuffie, Anal. Chem. 1970, 42, 1741.

[12] G. Gritzner, J. Kuta, Pure Appl. Chem. 1984, 56, 461.

[13] H. J. Paul, J. Leddy, Anal. Chem. 1995, 67, 1661.

[14] A. J. Bard, L. R. Faulkner, in Electrochemical methods: fundamentals and applications, Wiley, New York, $2^{\text {nd }}$ Ed., 2001. 
[15] T. Weitner, I. Kos, Z. Mandić, I. Batinić-Haberle, M. Biruš, Dalton Trans. 2013, 42, 14757.

[16] D. H. Evans, K. M. O'Connell, R. A. Petersen, M. J. Kelly, J. Chem. Educ. 1983, 60, 290.

[17] R. S. Nicholson, Anal. Chem. 1965, 37, 1351.

[18] N. Saha, B. Das, J. Chem. Eng. Data 2000, 45, 1125.

[19] Gaussian 09, Revision D.01, M. J. Frisch, G. W. Trucks, H. B. Schlegel, G. E. Scuseria, M. A. Robb, J. R. Cheeseman, G. Scalmani, V. Barone, B. Mennucci, G. A. Petersson, H. Nakatsuji, M. Caricato, X. Li, H. P. Hratchian, A. F. Izmaylov, J. Bloino, G. Zheng, J. L. Sonnenberg, M. Hada, M. Ehara, K. Toyota, R. Fukuda, J. Hasegawa, M. Ishida, T. Nakajima, Y. Honda, O. Kitao, H. Nakai, T. Vreven, J. A. Montgomery, Jr., J. E. Peralta, F. Ogliaro, M. Bearpark, J. J. Heyd, E. Brothers, K. N. Kudin, V. N. Staroverov, R. Kobayashi, J. Normand, K. Raghavachari, A. Rendell, J. C. Burant, S. S. lyengar, J. Tomasi, M. Cossi, N. Rega, J. M. Millam, M. Klene, J. E. Knox, J. B. Cross, V. Bakken, C. Adamo, J. Jaramillo, R. Gomperts, R. E. Stratmann, O. Yazyev, A. J. Austin, R. Cammi, C. Pomelli, J. W. Ochterski, R. L. Martin, K. Morokuma, V. G. Zakrzewski, G. A. Voth, P. Salvador, J. J. Dannenberg, S. Dapprich, A. D. Daniels, Ö. Farkas, J. B. Foresman, J. V. Ortiz, J. Cioslowski, and D. J. Fox, Gaussian, Inc., Wallingford CT, 2009.

[20] M. Dolg, U. Wedig, H. Stoll, H. Preuß, J. Chem. Phys. 1987, 86, 866.

[21] T. Romero, A. Caballero, A. Espinosa, A. Tárraga, P. Molina, Dalton Trans. 2009, 2121.

[22] M. Cossi, G. Scalmani, N. Rega, V. Barone, J. Chem. Phys. 2002, 117, 43.
[23] V. Barone, M. Cossi, J. Tomasi, J. Chem. Phys. 1997, 107, 3210.

[24] A. Houlton, C. J. Isaac, A. E. Gibson, B. R. Horrocks, W. Clegg, M. R. J. Elsegood, J. Chem. Soc. Dalton Trans. 1999, 3229.

[25] A. V. Marenich, J. Ho, M. L. Coote, C. J. Cramer, D. G. Truhlar, Phys. Chem. Chem. Phys. 2014, 16, 16068.

[26] M. Isegawa, F. Neese, D. A. Pantazis, J. Chem. Theory Comput. 2016, 12, 2272.

[27] H. Wang, C. Yu, Res. Chem. Intermed. 2010, 36, 1003.

[28] B. T. Psciuk, R. L. Lord, B. H. Munk, H. B. Schlegel, J. Chem. Theory Comput. 2012, 8, 5107.

[29] M. Namazian, C. Y. Lin, M. L. Coote, J. Chem. Theory Comput. 2010, 6, 2721.

[30] B. Thapa, H. B. Schlegel, J. Phys. Chem. A 2015, 119, 5134.

[31] S. J. Konezny, M. D. Doherty, O. R. Luca, R. H. Crabtree, G. L. Soloveichik, V. S. Batista, J. Phys. Chem. C 2012, 116, 6349.

[32] M. M. Flores-Leonar, R. Moreno-Esparza, V. M. Ugalde-Saldivar, C. Amador-Bedolla, Comp. Theor. Chem. 2017, 1099, 167.

[33] Y. Paukku, G. Hill, J. Phys. Chem. A 2011, 115, 4804.

[34] K. Lewis, K. Copeland, G. Hill, Int. J. Quant. Chem. 2014, 114, 1678.

[35] R. Martinez, A. Tiripicchio, Acta Cryst. 1990, CA6, 202.

[36] J. Ho, M. L. Coote, C. J. Cramer, D. G. Truhlar in Organic Electrochemistry, $5^{\text {th }}$ Ed. (Eds: O. Hammerich, B. Speiser), CRC Press, Boca Raton, FL, 2015, pp. 229-263. 